\title{
Diagnostic and medical needs for therapeutic drug monitoring of antibiotics
}

\author{
Claude Mabilat ${ }^{1} \cdot$ Marie Francoise Gros ${ }^{1} \cdot$ David Nicolau $^{2} \cdot$ Johan W. Mouton $^{3}$ • Julien Textoris ${ }^{1}$ • Jason A. Roberts ${ }^{4,5,6}$. \\ Menino O. Cotta ${ }^{4,5,6}$. Alex van Belkum ${ }^{7} \cdot$ Isabelle Caniaux $^{1}$
}

Published online: 11 December 2019

(C) The Author(s) 2019

\begin{abstract}
Therapeutic drug monitoring (TDM) of antibiotics has been practiced for more than half a century, but it is still not widely applied for infected patients. It has a traditional focus on limiting toxicity of specific classes of antibiotics such as aminoglycosides and vancomycin. With more patients in critical care with higher levels of sickness severity and immunosuppression as well as an increasingly obese and ageing population, an increasing risk of suboptimal antibiotic exposure continues to escalate. As such, the value of TDM continues to expand, especially for beta-lactams which constitute the most frequently used antibiotic class. To date, the minimum inhibitory concentration (MIC) of infectious microbes rather than classification in terms of susceptible and resistant can be reported. In parallel, increasingly sophisticated TDM technology is becoming available ensuring that TDM is feasible and can deliver personalized antibiotic dosing schemes. There is an obvious need for extensive studies that will quantify the improvements in clinical outcome of individual TDM-guided dosing. We suggest that a broad diagnostic and medical investigation of the TDM arena, including market analyses and analytical technology assessment, is a current priority.
\end{abstract}

\section{Introduction}

The need for precise measurement of antimicrobial agents in the blood of patients to follow treatment success or failure was

Author Johan W. Mouton has passed away before the official publication of the article.

Claude Mabilat

claude.mabilat@biomerieux.com

Medical Affairs, bioMérieux, Marcy l'Étoile, Lyon, France

2 Center for Anti-Infective Research \& Development, Hartford Hospital, 80 Seymour Street, Hartford, CT 06102, USA

3 Department of Medical Microbiology and Infectious Diseases, Erasmus University Medical Centre, Rotterdam, Dr Molewaterplein 40, 3015 GD Rotterdam, Netherlands

4 Centre for Clinical Research, Faculty of Medicine, The University of Queensland, Brisbane, Queensland, Australia

5 School of Pharmacy, The University of Queensland, Brisbane, Queensland, Australia

6 Pharmacy Department, Royal Brisbane and Women's Hospital, Brisbane, Queensland, Australia

7 Data Analytics Department, bioMérieux, La Balme Les Grottes, Grenoble, France recognized early on [1]. Traditionally, this therapeutic drug monitoring (TDM) of antibiotics has primarily involved quantitative drug measurements in patient's plasma to minimize toxicity risks with agents of narrow therapeutic indices [2, 3]. Still for antibiotics, TDM was used sparingly such as for vancomycin, chloramphenicol and the aminoglycosides [4]. The general target population were and still are patients in acute care situations or those hospitalized for longer term care and treatment (e.g. [5]). A more advanced TDM practice, however, is emerging with an aim to ensure efficacy as well as minimizing toxicity of a broader spectrum of antibiotics with relatively wider therapeutic indices. It takes advantage of a better definition of the optimum antibiotic exposure for therapeutic success. Antibiotic pharmacokinetics (PK) is commonly defined as 'what does the body do to the drug' during its complete cycle in vivo, whereas pharmacodynamics (PD) relates to 'what the drug does to the microorganism in vivo', the interplay between the two, 'PK/PD', defining the optimum antimicrobial activity achievable for the unbound drug concentrations at the site of infection. Consensus studies and guidelines have helped to propose values for these PK/PD targets, specific for an antibiotic in combination with a clinical condition [6-8]. By comparing drug plasma concentration data (a surrogate for the site of infection) to these predefined PK/PD targets, a personalized antibiotic dosing practice can help ensure an optimized antibiotic exposure. Personalized treatment will apply to an 
increasing population of high-risk patients and will have additional impact on the fight against antimicrobial resistance (AMR) by significantly improving the optimal usage of our pharmacopoeia. Finally, a reduced developmental pipeline for new antibiotics is necessitating that we spare last resort drugs with TDM considered instrumental for protecting this precious antimicrobial armamentarium (e.g. [9]).

Here, we succinctly review the current status of TDM in the field of antibiotic therapy. Despite the fact that significant progress has been made in various disciplines in the field of TDM, there still seems to be a restricted global implementation.

\section{Sub-optimal antibiotic exposure in high-risk patient groups}

The majority of drug dosing regimens has been defined in healthy adults at the time of drug development where there was no resistance to those drugs. The lack of variability in PK and patient characteristics in those initial studies is not a representative of the breadth of patients in whom these drugs will be used and the ultimate exposure levels of such patients. It is highly unlikely that this "one dose fits all" strategy will maximize antibiotic effectiveness in all patients. Unpredictable drug concentrations in plasma and other body compartments due to altered volume of distribution and clearance may result from factors as diverse as acute pathophysiology during critical care admission (such as sepsis and immuno-suppression), obesity [10], early ages [11], advanced age, surgical prophylaxis for longer invasive procedures [12], cystic fibrosis [13], the use of techniques for organ replacement in case of organ failure (extracorporeal membrane oxygenation (ECMO)) and renal replacement therapy (RRT) [14, 15]. To add to these significant alterations of $\mathrm{PK}$ in critically ill patients, the PD target might be different depending on the indications. (e.g. skin and soft tissue versus pulmonary infections).

As a consequence, a growing body of evidence links subtherapeutic antibiotic concentrations with treatment failure. For example, the "Defining Antibiotic Levels in Intensive Care Unit (ICU) patients" (DALI) study showed that up to $70 \%$ of critically ill patients in the ICU did not meet the PK/ PD targets defined for beta-lactams, and that those patients with the lowest exposures were more likely to have a negative treatment outcome (treatment course with change or addition of antibiotic therapy, in particular within $48 \mathrm{~h}$ of cessation) [16]. Similar data are available for other antibiotics including meropenem [17], other beta-lactams [18-20], vancomycin [21-23], and ciprofloxacin [22, 24]. Both the studies by Moise-Broder et al. [21] and Martirosov et al. [23] show significant differences between optimal and suboptimal treatment of staphylococcal infection where the area under the curve (AUC) for $24 \mathrm{~h}$ of treatment below or under the minimum inhibitory concentration (MIC) value is statistically significant. The combined analysis of 179 patients clearly show that optimal vancomycin dosing is an important denominator of clinical and microbiological success. The use and therapeutic success of intravenous ciprofloxacin in 74 patients was shown to be dosing dependent [24]. Low dosing at $200 \mathrm{mg}$ for every $12 \mathrm{~h}$ versus higher dosing at $400 \mathrm{mg}$ every $8 \mathrm{~h}$ resulted in different overall drug concentrations in the blood and were clearly associated with slower eradication of the infecting organism in the low concentration treatment group. Of note, additional patient' characteristics have a distinct effect on antibiotic concentration in the circulation. Carrie et al. [20] show that augmented renal clearance of beta-lactams resulted in suboptimal antibiotic concentrations in serum for $12 \%$ of the patients and with that a significant effect on clinical and bacterial cure. Sub-optimal dosing and its clinical consequences is a domain of important research that should be thoroughly included in any development protocol for new antimicrobials.

\section{Optimized dosing for reducing selection of resistance}

The decreasing antibiotic susceptibility of pathogens may require higher antimicrobial dosing to achieve a therapeutic exposure that maximizes treatment success [25]. Still, dosing regimens for a new drug are initially defined by targeting 'wild type' susceptible pathogens, from which are derived the so-called ecological cut-off values (ECOFF) (MIC distribution separating bacterial populations into wild type and those with acquired or mutational resistance, see for instance [26] or the European Committee for Antimicrobial Susceptibility Testing (EUCAST) definition of wild type bacterial isolates). When a non-wild type pathogen emerges, higher doses may have to be used even if its higher MIC still falls within the susceptible or in the intermediate categories. As physicians tend to exclude antibiotics associated with intermediate MICs in favour of alternative antibiotics for which the bacterial strain is still fully susceptible, potent broad spectrum antimicrobials are often used [27]. Within this context, the EUCAST and Clinical and Laboratory Standards Institute (CLSI) committees recently promoted new increased dosing regimen categories in order to help spare last resort antibiotics (see EUCAST (www.eucast.org) and CLSI (www.clsi.org) websites for more detail). Thus, the dynamics of what the antibiotic does to the infectious bacteria in vivo has to be revised according to the MIC of the strain. EUCAST representatives suggest to integrate inherent experimental variability of MIC testing into the calculation of PK/PD targets by applying the following rules [28]. First, if the MIC is in the wild type category (susceptible organism) and lower than the ECOFF, then the ECOFF value should be used as the MIC value in the calculation of the PK/PD index. Second, if the 
MIC is above the ECOFF, then a $\times 4$ MIC value should be used. Thus, stricter adherence to antimicrobial susceptibility testing (AST) guidelines will make the data generated by TDM even more clinically useful. It has to be acknowledged though that MICs represent a marker based on a single point in time and concentration. In addition, measuring an MIC is no sinecure and significant variability within and between methods exists [29]. Not everything will be solved by simple adherence to guidelines, and there is a need for further studies into optimized dosing as a consequence of regional prevalence of antibiotic resistance [30].

\section{Patient outcomes and PK/PD target attainment}

An increased body of knowledge provides evidence for benefits associated with PK/PD target attainment, including variations in the dosing schemes, in terms of lower mortality, clinical cure, reduced length of stay and lower toxicity, as shown for many antibiotics. For example, continuous infusion as opposed to short-term infusion can help to reach more effective PK/PD targets and improve efficacy in case of sepsis where mortality can be reduced up to $30 \%$ [31,32]. Vancomycin [33, 34], beta-lactams [35, 36], aminoglycosides [37, 38], quinolones [24, 39], linezolid [40], daptomycin [41] and even antifungals [42] have been studied in adequate detail although it has to be admitted that not all studies uniformly showed clinical benefit.

Few studies have evaluated the impact of active TDM per se on the clinical course of critical care patients in prospective randomized trials [43], except maybe in the on-going "DIABOLO" and "OPTIMAL TDM" clinical trials [44]. These studies show that TDM improves antibiotic exposure by guiding PK/PD target attainment. This will potentially help reduce the early development of antibiotic resistance as evidenced in preclinical infection models $[45,46]$ and adds weight to the call for active TDM of all patients, for which high PK variability is expected. This is corroborated by Jacobs et al. [47] who showed that a simple creatinine clearance measure cannot be used to predict and adjust the beta-lactam plasma concentration in septic patients with augmented renal clearance [48]. Independently, TDM was proven to be cost-effective for streamlining aminoglycoside use [49]. This can only be true for newer, hence more costly antibiotics. Thus, it can be concluded that, if managed correctly, TDM is profitable for patient management and the health economy simultaneously.

\section{Monitoring of antibiotic concentrations today}

From a historical perspective, TDM has been adopted mostly to prevent adverse toxicity effects, mainly for glycopeptides and aminoglycosides. Apart from the assessment of trough concentrations, also the determination of peak concentrations was considered to be diagnostically and, hence, therapeutically important. TDM of trough concentrations still is strongly recommended for all patients using the aforementioned antibiotics $[17,50]$.

However, TDM is now on a slow rise in broader use to ensure optimum antibiotic exposure, in particular to avoid under-dosing, with evidence existing for many antibiotic classes including beta-lactams, linezolid and daptomycin (see statements above). With regard to beta-lactams, the most commonly monitored drugs are piperacillin-tazobactam and meropenem, followed by ceftazidime [51]. Data required include the concentration of the antibiotic in the patient's plasma, which is quantified either by a specialized pharmacology or biochemistry laboratory, as well as the MIC of the infectious microorganism, a result originating from the microbiology lab. These data are then consolidated with other clinical parameters (patient weight, comorbidities, renal function, etc.) TDM may be managed by routine hospital laboratories or more specialized independent laboratories either or not "Clinical Laboratory Improvement Amendments" (CLIA) compatible or waived.

\section{Technologies used for TDM}

The most commonly used method for current TDM involves immunological assaying, mostly using closed systems and automated chains. These are used in commercial kits for 'toxic' antibiotics like vancomycin and aminoglycosides and are mostly appreciated for their rapidity. However, standardization and calibration of this type of testing is not always easy. Immunoassays are often adapted to open chemistry mainstream chains to lower the overall cost (e.g. CEDIA by ThermoFisher Scientific and Roche, enzyme multiplied immunoassay technique (EMIT) by Olympus Chemistry Systems and the tests provided by Randox Laboratories (Crumlin, UK)).

The second most used technology is that of liquid chromatography (LC) which is often combined with mass spectrometry (LC-MS). LC-MS uses mostly locally developed assays and protocols, which provides a level of experimental flexibility that can be easily adapted to commonly applied antibiotics. LC-MS is a highly adaptable technology, and when internal standard molecular markers are available and the equipment and associated personnel are within financial reach, this is a good diagnostic choice. On the other hand, duration of MS technologies (24-96 h) may pose a significant obstacle to clinical use. Application of LC-MS requires the employment of an expert scientist which makes a 24-h service difficult. The technology is not available in all laboratories but mainly in metropolitan-based laboratories which often leads 
to delayed or prolonged time to result. Actually, various forms of point of care testing are currently being developed and prototypes are being experimented with. The use of biosensor technologies has been proposed, superficially explored and the first results are promising [52-54]. In the latter study, elegant microneedle-based biosensors were used for betalactam detection. Recent publications revealed the successful use of microfluidic devices for monitoring aminoglycoside or beta-lactam concentrations in whole blood with a wide dynamic range $[55,56]$. The development of such miniaturized and potentially automatable methods can better position TDM in routine microbiology laboratories, particularly if they are shown to be cost-effective. The assaying of body fluids that can be obtained non-invasively may make TDM more feasible [57]. The major current need are large-scale clinical validation studies for these new technologies. As stated before: none of the currently available methods adequately distinguished between the bound and unbound fractions of antibiotics.

\section{Clinical timing of TDM}

It is suggested that for clinical application of TDM, one or two TDM measurements should be made during the very first dosing interval of the antibiotic treatment, then updated as much as needed after $48 \mathrm{~h}$ or before, depending on the antibiotic. The data can then be compared with PK models for specific populations, now available in any one of various software solutions that estimate the dose to use [58]. In practice, this is difficult because antibiotics might have short half-lives ( $4 \mathrm{~h}$ and $6 \mathrm{~h}$ on average for $\beta$-lactams and vancomycin, respectively). Defining the best sampling time may be problematic since the prescription strategy often relies on repeated antibiotic administration. This underlines the need for welldocumented, written protocols for managing TDM. Another challenge is that the total turnaround time (TAT) of TDM may be too long if the required expertise is not available as a permanent service. This includes the need for sometimes complicated and lasting pre- and post-analytical procedures; total TDM TAT ranges between $2 \mathrm{~h}$ to sometimes even $24 \mathrm{~h}$, averaging 18-24 h (personal communications with various TDM users). With the actual TDM test being relatively quick in itself (ca. $30 \mathrm{~min}$ ), the overall TAT is limited by logistics and pre- and post-analytical processes. This underscores the need for a simple-to-operate and easy-to-interpret test that must be continuously available to help increase the operability of TDM.

Of additional interest is the previously already mentioned use of continuous infusion of antibiotics in the ICU $[31,59]$. The first intelligent devices that can perform this in an intrinsically controlled fashion using concentration-based feedback mechanisms are becoming tested in this field [60]. This also translates into a considerable practical interest for TDM because once the initial loading dose has attained its equilibrium, sampling and TDM can be done at any time, therefore removing time constraint and kinetic uncertainty and enabling a smoother use of TDM in the patient management workflow [61]. In addition, the use of machine learning procedures to develop algorithms that facilitate software-driven timing-independent adaptation of individual treatment will become more widespread in the near future.

\section{Conclusion and recommendation}

TDM should be clearly positioned as an integral part of the antimicrobial stewardship program in hospitals given its pivotal role in antibiotic treatment optimization. This will enable better delivery of the right antibiotic dose for the right patient at the right moment and for the right duration. As such, it will help combat the challenges provided by the growing AMR problem. This personalized medicine perspective still requires improvement to fully satisfy antibiotic prescribers. It is urgent that the TAT of TDM be shortened significantly and that accessible point of care tests and rapid technology-based assays enter the TDM market. Also, here are many practical questions around the implementation of TDM. How to coordinate results coming from microbiology and clinical chemistry laboratories? Who will integrate the data and issue a therapeutic advice? Who will be adjusting antimicrobial therapy and along which guidelines? When these issues have been resolved, TDM should become an integral part of the standard testing portfolio of all self-respecting clinical microbiology laboratories.

Open Access This article is licensed under a Creative Commons Attribution 4.0 International License, which permits use, sharing, adaptation, distribution and reproduction in any medium or format, as long as you give appropriate credit to the original author(s) and the source, provide a link to the Creative Commons licence, and indicate if changes were made. The images or other third party material in this article are included in the article's Creative Commons licence, unless indicated otherwise in a credit line to the material. If material is not included in the article's Creative Commons licence and your intended use is not permitted by statutory regulation or exceeds the permitted use, you will need to obtain permission directly from the copyright holder. To view a copy of this licence, visit http://creativecommons.org/licenses/by/4.0/.

\section{References}

1. Kirkman AC (1956) A review of bacteriological sensitivity tests and a capillary tube method for the determination of antibiotic levels in the body fluids. Cent Afr J Med 2(10):367-369

2. Begg EJ, Barclay ML, Kirkpatrick CJ (1999) The therapeutic monitoring of antimicrobial agents. Br J Clin Pharmacol 47(1):23-30 Review 
3. Begg EJ, Barclay ML, Kirkpatrick CJ (2001) The therapeutic monitoring of antimicrobial agents. Br J Clin Pharmacol 52(Suppl 1): $35 \mathrm{~S}-43 \mathrm{~S}$

4. Wenk M, Vozeh S, Follath F (1984) Serum level monitoring of antibacterial drugs. A review. Clin Pharmacokinet 9(6):475-492 Review

5. Mattioli F, Fucile C, Del Bono V, Marini V, Parisini A, Molin A, Zuccoli ML, Milano G, Danesi R, Marchese A, Polillo M, Viscoli C, Pelosi P, Martelli A, Di Paolo A (2016) Population pharmacokinetics and probability of target attainment of meropenem in critically ill patients. Eur J Clin Pharmacol 72(7):839-848. https://doi. org/10.1007/s00228-016-2053-x

6. Roberts JA, Abdul-Aziz MH, Lipman J, Mouton JW, Vinks AA, Felton TW, Hope WW, Farkas A, Neely MN, Schentag JJ, Drusano G, Frey OR, Theuretzbacher U, Kuti JL, International Society of Anti-Infective Pharmacology and the Pharmacokinetics and Pharmacodynamics Study Group of the European Society of Clinical Microbiology and Infectious Diseases (2014) Individualised antibiotic dosing for patients who are critically ill: challenges and potential solutions. Lancet Infect Dis 14(6):498509. https://doi.org/10.1016/S1473-3099(14)70036-2

7. Felton TW, Hope WW, Roberts JA (2014) How severe is antibiotic pharmacokinetic variability in critically ill patients and what can be done about it? Diagn Microbiol Infect Dis 79(4):441-447. https:// doi.org/10.1016/j.diagmicrobio.2014.04.007

8. Muller AE, Huttner B, Huttner A (2018) Therapeutic drug monitoring of beta-lactams and other antibiotics in the intensive care unit: which agents, which patients and which infections? Drugs. 78(4):439-451. https://doi.org/10.1007/s40265-018-0880-z

9. Li J, Burzynski JN, Lee YA, Berg D, Driver CR, Ridzon R, Munsiff SS (2004) Use of therapeutic drug monitoring for multidrugresistant tuberculosis patients. Chest. 126(6):1770-1776

10. Boyd SE, Charani E, Lyons T, Frost G, Holmes AH (2016) Information provision for antibacterial dosing in the obese patient: a sizeable absence? J Antimicrob Chemother 71(12):3588-3592

11. Stickland MD, Kirkpatrick CM, Begg EJ, Duffull SB, Oddie SJ, Darlow BA (2001) An extended interval dosing method for gentamicin in neonates. J Antimicrob Chemother 48(6):887-893

12. Hollis AL, Heil EL, Nicolau DP, Odonkor P, Dowling TC, Thom KA (2015) Validation of a dosing strategy for cefazolin for surgery requiring cardiopulmonary bypass. Surg Infect 16(6):829-832. https://doi.org/10.1089/sur.2014.250

13. Delfino E, Fucile C, Del Bono V, Marchese A, Marini V, Coppo E, Casciaro R, Minicucci L, Giacobbe DR, Martelli A, Viscoli C, Mattioli F (2018) Pharmacokinetics of high-dose extended-infusion meropenem during pulmonary exacerbation in adult cystic fibrosis patients: a case series. New Microbiol 41(1):47-51

14. Jamal JA, Economou CJ, Lipman J, Roberts JA (2012) Improving antibiotic dosing in special situations in the ICU: burns, renal replacement therapy and extracorporeal membrane oxygenation. Curr Opin Crit Care 18(5):460-471. https://doi.org/10.1097/MCC. 0b013e32835685ad

15. Jamal JA, Mueller BA, Choi GY, Lipman J, Roberts JA (2015) How can we ensure effective antibiotic dosing in critically ill patients receiving different types of renal replacement therapy? Diagn Microbiol Infect Dis 82(1):92-103. https://doi.org/10.1016/j. diagmicrobio.2015.01.013

16. Roberts JA, Paul SK, Akova M, Bassetti M, De Waele JJ, Dimopoulos G, Kaukonen KM, Koulenti D, Martin C, Montravers P, Rello J, Rhodes A, Starr T, Wallis SC, Lipman J, DALI study (2014) DALI: defining antibiotic levels in intensive care unit patients: are current $\beta$-lactam antibiotic doses sufficient for critically ill patients? Clin Infect Dis 58(8):1072-1083. https:// doi.org/10.1093/cid/ciu027
17. Li C, Du X, Kuti JL, Nicolau DP (2007) Clinical pharmacodynamics of meropenem in patients with lower respiratory tract infections. Antimicrob Agents Chemother 51(5):1725-1730

18. McKinnon PS, Paladino JA, Schentag JJ (2008) Evaluation of area under the inhibitory curve (AUIC) and time above the minimum inhibitory concentration ( $\mathrm{T}>\mathrm{MIC}$ ) as predictors of outcome for cefepime and ceftazidime in serious bacterial infections. Int $\mathrm{J}$ Antimicrob Agents 31(4):345-351. https://doi.org/10.1016/j. ijantimicag.2007.12.009

19. Abdulla A, Hunfeld N, Dijkstra A, Duran S, Mouton J, Gommers D, van Gelder T, Koch B (2017) Beta-lactam and quinolone pharmacokinetic/pharmacodynamic target attainment in critically ill patients (EXPAT). Abstr ECCMID 2017(April):12-13

20. Carrié C, Petit L, d'Houdain N, Sauvage N, Cottenceau V, Lafitte M, Foumenteze C, Hisz Q, Menu D, Legeron R, Breilh D, Sztark F (2018) Association between augmented renal clearance, antibiotic exposure and clinical outcome in critically ill septic patients receiving high doses of $\beta$-lactams administered by continuous infusion: a prospective observational study. Int J Antimicrob Agents 51(3): 443-449. https://doi.org/10.1016/j.ijantimicag.2017.11.013

21. Moise-Broder PA, Forrest A, Birmingham MC, Schentag JJ (2004) Pharmacodynamics of vancomycin and other antimicrobials in patients with Staphylococcus aureus lower respiratory tract infections. Clin Pharmacokinet 43(13):925-942

22. Rybak MJ, Lomaestro BM, Rotschafer JC, Moellering RC, Craig WA, Billeter M, Dalovisio JR, Levine DP (2009) Vancomycin therapeutic guidelines: a summary of consensus recommendations from the infectious diseases Society of America, the American Society of Health-System Pharmacists, and the Society of Infectious Diseases Pharmacists. Clin Infect Dis 49(3):325-327. https://doi.org/10. 1086/600877

23. Martirosov D, Bidell M, Pai M, Scheetz M, Rosenkranz S, Lodise T (2017) Relationship between vancomycin exposure and outcomes among patients with MRSA bloodstream infections with vancomycin Etest ${ }^{\circledR}$ MIC values of $1.5 \mathrm{mg} / \mathrm{L}$ : a pilot study. Diagn Microbiol Infect Dis 88. https://doi.org/10.1016/j.diagmicrobio.2017.03.008

24. Forrest A, Nix DE, Ballow CH, Goss TF, Birmingham MC, Schentag JJ (1993) Pharmacodynamics of intravenous ciprofloxacin in seriously ill patients. Antimicrob Agents Chemother 37: 1073-1081

25. Fernández de Gatta M, Santos Buelga D, Sánchez Navarro A, Dominguez-Gil A, García MJ (2009) Vancomycin dosage optimization in patients with malignant haematological disease by pharmacokinetic/pharmacodynamic analysis. Clin Pharmacokinet 48(4):273-280. https://doi.org/10.2165/00003088-20094804000005

26. Arendrup MC, Prakash A, Meletiadis J, Sharma C, Chowdhary A (2017) Comparison of EUCAST and CLSI reference microdilution MICs of eight antifungal compounds for Candida auris and associated tentative epidemiological cutoff values. Antimicrob Agents Chemother 61(6):e00485-e00417. https://doi.org/10.1128/AAC. 00485-17

27. Lopez B, Siqueira de Oliveira R, Pinhata JMW, Chimara E, Pacheco Ascencio E, Puyén Guerra ZM, Wainmayer I, Simboli N, Del Granado M, Palomino JC, Ritacco V, Martin A. Bedaquiline and linezolid MIC distributions and epidemiological cut-off values for Mycobacterium tuberculosis in the Latin American region. J Antimicrob Chemother 2019;74(2):373-379. doi: https://doi.org/10.1093/jac/dky414

28. Mouton JW, Muller AE, Canton R, Giske CG, Kahlmeter G, Turnidge J (2018) MIC-based dose adjustment: facts and fables. J Antimicrob Chemother 73(3):564-568. https://doi.org/10.1093/jac/ $\mathrm{dkx} 427$

29. Leclercq R, Cantón R, Brown DF, Giske CG, Heisig P, MacGowan AP, Mouton JW, Nordmann P, Rodloff AC, Rossolini GM, Soussy CJ, Steinbakk M, Winstanley TG, Kahlmeter G (2013) EUCAST 
expert rules in antimicrobial susceptibility testing. Clin Microbiol Infect 19(2):141-160. https://doi.org/10.1111/j.1469-0691.2011. 03703.x

30. Tam VH, Chang KT, Zhou J, Ledesma KR, Phe K, Gao S, Van Bambeke F, Sánchez-Díaz AM, Zamorano L, Oliver A, Cantón R (2017) Determining $\beta$-lactam exposure threshold to suppress resistance development in gram-negative bacteria. J Antimicrob Chemother 72(5):1421-1428. https://doi.org/10.1093/jac/dkx001

31. Roberts JA, Abdul-Aziz MH, Davis JS, Dulhunty JM, Cotta MO, Myburgh J, Bellomo R, Lipman J (2016) Continuous versus intermittent $\beta$-lactam infusion in severe sepsis. A meta-analysis of individual patient data from randomized trials. Am J Respir Crit Care Med 194(6):681-691. https://doi.org/10.1164/rccm.201601$0024 \mathrm{OC}$

32. Vardakas KZ, Voulgaris GL, Maliaros A, Samonis G, Falagas ME (2018) Prolonged versus short-term intravenous infusion of antipseudomonal $\beta$-lactams for patients with sepsis: a systematic review and meta-analysis of randomised trials. Lancet Infect Dis 18(1):108-120. https://doi.org/10.1016/S1473-3099(17)30615-1

33. Jumah MTB, Vasoo S, Menon SR, De PP, Neely M, Teng CB (2018) Pharmacokinetic/pharmacodynamic determinants of vancomycin efficacy in enterococcal bacteremia. Antimicrob Agents Chemother 62(3):e01602-e01617. Published 2018 Feb 23. https:// doi.org/10.1128/AAC.01602-17

34. Zelenitsky SA, Harding GK, Sun S, Ubhi K, Ariano RE (2003) Treatment and outcome of Pseudomonas aeruginosa bacteraemia: an antibiotic pharmacodynamic analysis. J Antimicrob Chemother 52(4):668-674

35. Abdul-Aziz MH, Sulaiman H, Mat-Nor MB, Rai V, Wong KK, Hasan MS, Abd Rahman AN, Jamal JA, Wallis SC, Lipman J, Staatz CE, Roberts JA (2016) Beta-Lactam Infusion In Severe Sepsis (BLISS): a prospective, two-centre, open-labelled randomised controlled trial of continuous versus intermittent betalactam infusion in critically ill patients with severe sepsis. Intensive Care Med 42(10):1535-1545. https://doi.org/10.1007/s00134-0154188-0

36. Muller AE, Punt N, Mouton JW (2013) Optimal exposures of ceftazidime predict the probability of microbiological and clinical outcome in the treatment of nosocomial pneumonia. J Antimicrob Chemother 68(4):900-906. https://doi.org/10.1093/jac/dks468

37. Moore RD, Lietman PS, Smith CR (1987) Clinical response to aminoglycoside therapy: importance of the ratio of peak concentration to minimal inhibitory concentration. J Infect Dis 155(1):93-99

38. Zelenitsky S, Rubinstein E, Ariano R, Iacovides H, Dodek P, Mirzanejad Y, Kumar A (2013) The Cooperative Antimicrobial Therapy of Septic Shock (CATSS) database research group. Int J Antimicrob Agents 41(3):255-260

39. Ambrose PG, Grasela DM, Grasela TH, Passarell J, Mayer HB, Pierce PF (2001) Pharmacodynamics of fluoroquinolones against Streptococcus pneumoniae in patients with community-acquired respiratory tract infections. Antimicrob Agents Chemother 45: 2793-2797

40. Rayner CR, Forrest A, Meagher AK, Birmingham MC, Schentag JJ Clinical pharmadynamics of linezolid in seriously ill patients treated in a compassionate use programme. Clin. Pharmacokinet 42(15): $1411-1423$

41. Galar A, Muñoz P, Valerio M, Cercenado E, García-González X, Burillo A, Sánchez-Somolinos M, Juárez M, Verde E, Bouza E (2019) Current use of daptomycin and systematic therapeutic drug monitoring: clinical experience in a tertiary care institution. Int $\mathrm{J}$ Antimicrob Agents 53(1):40-48. https://doi.org/10.1016/j. ijantimicag.2018.09.015

42. Clancy CJ, Yu VL, Morris AJ, Snydman DR, Nguyen MH (2005) Fluconazole MIC and the fluconazole dose/MIC ratio correlate with therapeutic response among patients with candidemia. Agents Chemother 49(8):3171-3177
43. Roberts JA, Norris R, Paterson DL, Martin JH (2012) Therapeutic drug monitoring of antimicrobials. Br J Clin Pharmacol 73(1):2736. https://doi.org/10.1111/j.1365-2125.2011.04080.x

44. OPTIMAL TDM study. https://clinicaltrials.gov/ct2/show/ NCT03790631

45. Martinez MN, Papich MG, Drusano GL (2012) Dosing regimen matters: the importance of early intervention and rapid attainment of the pharmacokinetic/pharmacodynamic target. Antimicrob Agents Chemother 56(6):2795-2805. https://doi.org/10.1128/ AAC.05360-11

46. Vanscoy B, Mendes RE, Castanheira M, McCauley J, Bhavnani SM, Forrest A, Jones RN, Okusanya OO, Friedrich LV, Steenbergen J, Ambrose PG (2013) Relationship between ceftolozane-tazobactam exposure and drug resistance amplification in a hollow-fiber infection model. Antimicrob Agents Chemother 57(9):4134 4138. https://doi.org/10.1128/AAC.00461-13

47. Jacobs A, Taccone FS, Roberts JA, Jacobs F, Cotton F, Wolff F, Creteur J, Vincent JL, Hites M. $\beta$-Lactam dosage regimens in septic patients with augmented renal clearance. Antimicrob Agents Chemother. 2018;62(9). pii: e02534-e02517. doi: https://doi.org/ 10.1128/AAC.02534-17.

48. Roehr AC, Frey OR, Köberer A, Fuchs T, Helbig S, Brinkmann A, Mouton JW (2015) Creatinine-clearance as predictor for meropenem clearance. ESCMID Copenhagen, nr:EV0080

49. Van Lent-Evers NA, Mathôt RA, Geus WP, van Hout BA, Vinks AA (1999) Impact of goal-oriented and model-based clinical pharmacokinetic dosing of aminoglycosides on clinical outcome: a costeffectiveness analysis. Ther Drug Monit 21(1):63-73

50. Stockmann C, Roberts JK, Yu T, Constance JE, Knibbe CA, Spigarelli MG, Sherwin CM (2014) Vancomycin pharmacokinetic models: informing the clinical management of drug-resistant bacterial infections. Expert Rev Anti-Infect Ther 12(11):1371-1388. https://doi.org/10.1586/14787210.2014.966081

51. Wong G, Brinkman A, Benefield RJ, Carlier M, De Waele JJ, El Helali N, Frey O, Harbarth S, Huttner A, McWhinney B, Misset B, Pea F, Preisenberger J, Roberts MS, Robertson TA, Roehr A, Sime FB, Taccone FS, Ungerer JP, Lipman J, Roberts JA (2014) An international, multicentre survey of $\beta$ lactam antibiotic therapeutic drug monitoring practice in intensive care units. J Antimicrob Chemother 69(5):14161423. https://doi.org/10.1093/jac/dkt523

52. Arroyo-Currás N, Somerson J, Vieira PA, Ploense KL, Kippin TE, Plaxco KW (2017) Real-time measurement of small molecules directly in awake, ambulatory animals. Proc Natl Acad Sci U S A 114(4):645-650. https://doi.org/10.1073/pnas.1613458114

53. Rawson TM, O'Hare D, Herrero P, Sharma S, Moore LSP, de Barra E, Roberts JA, Gordon AC, Hope W, Georgiou P, Cass AEG, Holmes AH (2018) Delivering precision antimicrobial therapy through closed-loop control systems. J Antimicrob Chemother 73(4):835-843. https://doi.org/10.1093/jac/dkx458

54. Rawson TM, Gowers SAN, Freeman DME, Wilson RC, Sharma S, Gilchrist M, MacGowan M, Lovering A, Bayliss M, Kyriakides M, Georgiou P, Cass AE, O'Hare D, Holmes AH (2019) Microneedle biosensors for real-time, minimally invasive drug monitoring of phenoxymethylpenicillin: a first-in-human evaluation in healthy volunteers. Lancet Digital Health Published online September 30, 2019

55. Al-Aqbi ZT, Yap YC, Li F, Breadmore MC (2019) Integrated microfluidic devices fabricated in poly (methyl methacrylate) (PMMA) for on-site therapeutic drug monitoring of aminoglycosides in whole blood. Biosensors (Basel) 9(1):E19. https://doi.org/ 10.3390/bios9010019

56. Gowers SAN, Freeman DME, Rawson TM, Rogers ML, Wilson RC, Holmes AH, Cass AE, O'Hare D (2019) Development of a minimally invasive microneedle-based sensor for continuous monitoring of $\beta$-lactam antibiotic 
concentrations in vivo. ACS Sens 4(4):1072-1080. https:// doi.org/10.1021/acssensors.9b00288

57. Ghimire S, Maharjan B, Jongedijk EM, Kosterink JGW, Ghimire GR, Touw DJ, van der Werf TS, Shrestha B, Alffenaar JC. Evaluation of saliva as a potential alternative sampling matrix for therapeutic drug monitoring of levofloxacin in patients with multidrug-resistant tuberculosis. Antimicrob Agents Chemother. 2019;63(5). pii: e02379-e02318. doi: https://doi.org/10.1128/ AAC.02379-18

58. De Velde F, Mouton JW, de Winter BCM, van Gelder T, Koch BCP (2018) Clinical applications of population pharmacokinetic models of antibiotics: challenges and perspectives. Pharmacol Res 134: 280-288. https://doi.org/10.1016/j.phrs.2018.07.005

59. Rhodes NJ, Liu J, O'Donnell JN, Dulhunty JM, Abdul-Aziz MH, Berko PY, Nadler B, Lipman J, Roberts JA (2018)
Prolonged infusion piperacillin-tazobactam decreases mortality and improves outcomes in severely ill patients: results of a systematic review and meta-analysis. Crit Care Med 46(2): 236-243. https://doi.org/10.1097/CCM.0000000000002836

60. Alvarez-Lorenzo C, Concheiro A (2019) Smart drug release from medical devices. J Pharmacol Exp Ther. https://doi.org/10.1124/ jpet.119.257220

61. Mouton JW, Vinks AA (1996) Is continuous infusion of betalactam antibiotics worthwhile?-efficacy and pharmacokinetic considerations. J Antimicrob Chemother 38(1):5-15

Publisher's note Springer Nature remains neutral with regard to jurisdictional claims in published maps and institutional affiliations. 